\title{
Evaluación de las técnicas de detección del VPH en los programas de cribado para cáncer de cuello uterino
}

\author{
M Paz Cañadas, Lic, (') Belén Lloveras, Inmuno,, (2) Attila Lorincz, PhD, (3) Maijo Ejarque, Dr,,(1) \\ Rebeca Font, Lic, ${ }^{(2)}$ F. Xavier Bosch, Epidemiol, ${ }^{(2)}$ Silvia de Sanjosé, PhD. ${ }^{(2)}$
}

\section{Cañadas MP, Lloveras B, Lorincz A, Ejarque M, Font R, Bosch FX, De Sanjosé S. Evaluación de las técnicas de detección delVPH en los programas de cribado para cáncer de cuello uterino.} Salud Publica Mex 2006;48:373-378.

\section{Resumen}

Objetivo. La identificación de la infección por tipos de alto riesgo del virus del papiloma humano (VPH) es una herramienta útil para el cribado de cáncer del cuello uterino. Las distintas técnicas aplicadas para su detección deben contrastarse y validarse para su empleo en la tamización poblacional. Material y métodos. Se evalúan tres técnicas para la detección delVPH en 166 muestras cervicales procedentes de mujeres atendidas en una clínica de dermatología en Oviedo (España): a) PCR-EIA mediante consensos MY09/ MYOII; b) PCR con line blot hybridization (PCR-LBH) con consensos PGMY; y c) hybrid capture 2. Resultados. El ADNVPH se reconoció en $29.5 \%, 25.3 \%$ y $24.7 \%$, de acuerdo con el ensayo. La concordancia global entre PCR-EIA, PCR-LBH y $\mathrm{HC2}$ fue de $73.5 \%$ con los valores de kappa superiores a 0.56 entre los ensayos $(p<0.00 \mathrm{I})$. Conclusiones. La prevalencia de tipos de alto riesgo oncogénico así como de las lesiones fue similar en los tres ensayos. En virtud de que las técnicas son comparables, su elección debe basarse en las condiciones individuales de cada laboratorio y el volumen de muestras por procesar.

Palabras clave: virus del papiloma humano; cáncer de cérvix; neoplasia intraepitelial cervical; PCR; hibridacción; España
Cañadas MP, Lloveras B, Lorincz A, Ejarque M, Font R, Bosch FX, De Sanjosé S.

Assessment of HPV detection assays for use

in cervical cancer screening programs.

Salud Publica Mex 2006;48:373-378.

\begin{abstract}
Objective: Detection of high-risk human papillomavirus types (HPV) infection is an important tool in the screening of cervical cancer and triage of cytological abnormalities. The different techniques for detection of this cancer need to be contrasted and validated for use in population screening. Material and Methods: Cervical cell samples were collected from 166 women attending a dermatology clinic in Oviedo (Spain). We evaluated the performance of three different assays forVPH detection. The methods utilized were I) In-house PCR-EIA using LI consensus primers MY09/ MYII, 2) A PCR-reverse line blot hybridization (PCR-LBH) that uses LI consensus PGMY primers. 3) Hybrid Capture 2. All assays were performed blinded. The kappa statistic was used to test for global agreement between assay pairs. Results: HPV DNA was detected in 24,7\%, 25,3\% and 29,5\% of the women, respective to the assay. The overall agreement between the in-house PCR, PCR-LBH and HC2 was $(73.5 \%)$ with all kappa values between assay pairs exceeding $0.56(p<0.001)$. Conclusion:The three HPV assays were equally accurate in estimating high-risk HPV prevalence and HPV-related lesions. The method for HPV detection must be decided depending on the goals of the search (screening, follow-up or molecular studies).
\end{abstract}

Key words: human papillomavirus; cervical cancer; cervical intraepithelial neoplasia; PCR; hybridization; España

(I) Departamento de Biología Molecular, Laboratorio de Análisis, General Lab. Barcelona, España.

(2) Epidemiología y Registro del Cáncer, Institut Català d'Oncología, L'Hospitalet de Llobregat. España.

(3) Digene Corporation. Gaithersburg, Estados Unidos.

Solicitud de sobretiros: Dra. Silvia de Sanjosé. Servicio de Epidemiología y Registro del Cáncer, Instituto Catalán de Oncología. Gran Vía Km.2.7. 08907 L’Hospitalet, Barcelona. España.

Correo electrónico: s.sanjose@iconcologia.net 
$\mathrm{L}$ a infección persistente por ciertos tipos de virus del papiloma humano (VPH) es el factor de riesgo más importante para el desarrollo de cáncer de cérvix.

En la actualidad, la citología cervical es la herramienta más usada para el cribado del cáncer cervical. Sin embargo, dada la importancia de la infección por VPH como factor etiológico de esta tumoración, se ha propuesto la detección viral en los programas de cribado de cáncer cervical en algunos países ${ }^{1}$ y es una técnica aprobada en fecha reciente por la Organización Mundial de la Salud para la tamización primaria del cáncer de cuello uterino (http:/ / www.iarc.fr/pageroot / PRELEASES/pr151a.html). Con toda claridad, estos instrumentos dependen del desarrollo de las técnicas moleculares. Las técnicas deben tener la sensibilidad y especificidad necesarias, además de una buena reproducibilidad, para considerarlas óptimas y aplicarlas en la detección del VPH en la práctica clínica. Desde la introducción del diagnóstico Atypical squamous cells of unknown significance (ASC-US) en la clasificación de Bethesda ha resultado controversial la forma de atender a las pacientes con este diagnóstico. ${ }^{2,3}$ Es por ello que algunos autores han considerado ahora la identificación de la infección por VPH en mujeres con diagnóstico de ASC-US. ${ }^{4,5}$ La posibilidad de reducir el porcentaje de falsos negativos de citología en el primer cribado de la población y la incorporación de una prueba molecular de VPH son algunas de las razones para evaluar estas pruebas.

Hoy en día existen muchos protocolos descritos en publicaciones que se utilizan en los laboratorios para reconocer el VPH, pero se dispone de escasa información acerca de su sensibilidad, especificidad y reproducibilidad. La única excepción es la técnica captura de híbridos 2 para VPH (HC2, Digene Corporation, Gaithersburg, MA), que está disponible como método estandarizado y lo ha aprobado ya la Food and Drug Administration de Estados Unidos.

El objetivo del estudio es comparar los métodos diferentes para la detección del VPH (dos protocolos de PCR y HC2) en muestras clínicas y evaluar su utilización en la práctica clínica. En España, la prevalencia de la infección en la población general es baja, razón por la cual se seleccionó a un grupo de mujeres de alto riesgo para la infección por VPH para la comparación de los tres métodos.

Para evaluar de forma global las propiedades de los ensayos es preciso realizar una comparación directa de los resultados obtenidos con los tres ensayos. En consecuencia, se requiere este tipo de evaluación para elegir la prueba adecuada para una aplicación particular (estudio poblacional, cribado, pacientes con ASC-US) e informar los límites de interpretación de las técnicas.

\section{Material y métodos}

Se incluyó a un total de 166 mujeres atendidas para control común en el Hospital Monte Naranco de Oviedo en la clínica de dermatología y enfermedades de transmisión sexual durante el periodo de octubre de 1997 a marzo de 1999. Todas las mujeres incluidas declararon trabajar como prostitutas.

Después de firmar un consentimiento informado, todas las participantes se sometieron a un examen ginecológico y se obtuvieron muestras de exfoliados celulares mediante espátula de Ayre y cepillo cervical para estudio citológico y detección de ADN-VPH. Todas las muestras se almacenaron en $1 \mathrm{ml}$ de $0.1 \mathrm{M}$ PBS a $-20^{\circ} \mathrm{C}$ hasta su procesamiento. Se prepararon cuatro alícuotas y se remitieron a cuatro laboratorios diferentes para la detección del VPH (General Lab, Barcelona, España; Molecular Diagnostics, Londres, UK; Roche Molecular Systems, Alameda, Estados Unidos; e Institut Català d'Oncología, Barcelona, España). Este estudio doble ciego se efectuó entre los laboratorios señalados y los resultados se enviaron a una oficina central (Servicio de Epidemiología y Registro del Cáncer del Institut Català d'Oncología) donde se realizó el análisis estadístico.

1. PCR-EIA. La extracción del ADN se llevó a cabo mediante lisis con proteinasa $\mathrm{K}$ durante dos horas a $55^{\circ} \mathrm{C}$, con posterior inactivación a $95^{\circ} \mathrm{C}$ durante 10 minutos. Se utilizaron cinco microlitros de ADN extraído para el ensayo de PCR con los cebadores consenso MY09/MY011 que amplifican una región del gen L1 del VPH. La PCR se realizó en $50 \mu \mathrm{l}$ de reacción que contenía $2.5 \mathrm{mM}$ de $\mathrm{MgCl}_{2}, 10 \mathrm{mM}$ de Tris $\mathrm{HCl}, 50 \mathrm{mM}$ de $\mathrm{KCl}, 2 \mu \mathrm{M}$ de dNTP, $1 \mu \mathrm{M}$ de d-UTP-digoxigenina (DIG), 25 pmol de cada cebador y $1 \mathrm{U}$ de polimerasa Taq (Roche Diagnostics, S.L). La reacción de amplificación se efectuó durante 40 ciclos de $95^{\circ} \mathrm{C}, 55^{\circ} \mathrm{C}$ y $72^{\circ} \mathrm{C}$ por un minuto. Los cebadores PC04/GH20 se utilizaron para amplificar un fragmento gen humano de la globina beta como control interno de integridad del ADN y ausencia de inhibidores de la PCR. $4,6,7$

Se inmovilizaron en una microplaca sondas genéricas y de tipo específico para el VPH. Los productos de PCR marcados y desnaturalizados con $0.4 \mathrm{~N}$ de $\mathrm{NaOH}$ se hibridaron bajo condiciones de temperaturas astringentes y luego se detectaron mediante anticuerpos antidigoxigenina conjugados con peroxida y un sustrato colorimétrico. Las muestras positivas se probaron para los tipos de VPH 16, 18, 31, 33 y 39. Las muestras positivas 
para VPH que no se hibridaron con ninguna de estas sondas se clasificaron como VPH X.

2. PCR-reverse line blot hybridization (PCR-LBH). En fecha reciente, Roche ha desarrollado un ensayo con cebadores PGMY09/11 que amplifican también el gen L1 del VPH y cebadores para la globina beta PC04/GH20 como control positivo de la amplificación. La reacción de PCR se realizó con $5 \mathrm{ml}$ de ADN, dNTP (dATP, dCTP y dGTP [10 mM]; dUTP [30 mM]) y polimerasa AmpliTaq Gold DNA. Las condiciones de la PCR fueron las siguientes: 9 minutos a $95^{\circ} \mathrm{C}$ seguido de 40 ciclos de un minuto a $95^{\circ} \mathrm{C}$, un minuto a $55^{\circ} \mathrm{C}$ y un minuto a $72^{\circ} \mathrm{C}$. El producto de PCR se desnaturalizó (0.13 N de $\mathrm{NaOH})$ y se colocó en una bandeja de hibridación; la posterior tipificación se realizó mediante hibridación del producto de PCR en una tira con 27 sondas de VPH y dos sondas de globina beta ${ }^{(8)}$. Las sondas de VPH de alto riesgo incluidas fueron $16,18,31,33,35,39,45,51,52,55$, 56, 58, 59, 68, MM4, MM7 y MM9. La hibridación se efectuó a $53^{\circ} \mathrm{C}$ así como los lavados posteriores a la misma. La detección del producto biotinilado se realizó mediante incubación con conjugado de peroxidasa de antestreptovidina y a continuación se empleó un sustrato (tetrametilbencidina) para visualizar la reacción. Esta técnica se practicó en los laboratorios Roche Molecular Systems, Alameda, y Molecular Diagnostics, Londres.

3. Hybrid capture 2 (HC2). Este ensayo se basa en la hibridación con sondas de ARN complementarias de la secuencia genómica de 13 tipos de VPH de alto riesgo oncogénico $(16,18,31,33,35,39,45$, $51,52,56,58,59$ y 68$)$. Las células cervicales se lisaron en solución para liberar el ADN, el cual se desnaturalizó, y luego se incubaron con sondas de ARN en unas condiciones estrictas que permiten la formación del híbrido ARN-ADN. La estructura tridimensional específica de este híbrido la reconoce y captura un anticuerpo conjugado con fosfatasa alcalina que está ligado a las paredes de un pozo de microplaca. Los híbridos inmovilizados se detectaron mediante adición de un sustrato que reacciona con la fosfatasa alcalina y produce fotones. La luz emitida se mide en un luminómetro y se expresa como unidad relativa de luz (RLU). Este ensayo se efectuó en el laboratorio de VPH del Institut Català d'Oncología, Barcelona.

\section{Análisis estadístico}

Se utilizó la prueba de McNemar para comparar la tasa de positividad entre los diferentes ensayos. Debido a la concordancia tan notable entre los dos laboratorios que utilizaron PCR-LBH (sólo dos casos inconsistentes), los resultados de ambos laboratorios se combinaron para el análisis (los dos casos discordantes se consideraron positivos). La prueba estadística kappa se usó para relacionar los dos ensayos: PCR-LBH y PCR-EIA, PCR-LBH y HC2. Sólo se consideraron los tipos de alto riesgo identificados por los tres ensayos.

\section{Resultados}

La prevalencia de la detección de la infección por VPH en la población estudiada se encuentra en los límites de 24.7 a $29.5 \%$, de acuerdo con la técnica utilizada. Las diferencias entre los distintos ensayos para identificar VPH no fueron estadísticamente significativas (cuadro I). La concordancia global entre los tres ensayos fue de 122/166 (73.5\%). El valor de kappa para la comparación entre PCR-EIA y PCR-LBH fue de 0.59 $(p<0.00)$ y de $0.57(p<0.00)$ para PCR-LBH y HC2 . En ambas comparaciones el valor de la kappa se interpreta como la concordancia entre ensayos para reconocer muestras positivas o negativas. La prueba de McNemar no fue significativamente estadística en ambos casos, lo cual indica que los tres ensayos no diferían en la detección de muestras positivas.

De las 166 mujeres, 41.6\% (69/166) fue positivo para ADN del VPH cuando se consideró la positividad de los tres ensayos; se detectó en 49/166 por PCREIA, 42/166 por PCR-LBH y 41/166 por HC2.

La concordancia entre PCR-LBH y PCR-EIA fue de $84 \%$ (cuadro II). La tasa de detección fue mayor con PCR-EIA. La comparación entre los resultados obtenidos para los tipos de alto riesgo fue muy complicada debido al amplio espectro de tipos que detecta la PCRLBH en comparación con la PCR-EIA. Por lo tanto, la comparación específica se limitó a los tipos reconocidos por ambas técnicas. El VPH 16 fue el tipo más identificado por los dos ensayos. La concordancia en la

\section{Cuadro I \\ Detección de ADN-VPH mediante tres ensayos.}

\begin{tabular}{lcc} 
Ensayo & ADN-VPH +voltotal & (IC95\%) \\
PCR-EIA & $49 / 166$ & $29.5(26-33)$ \\
\hline PCR-LBH & $42 / 166$ & $25.3(29-22)$ \\
\hline HC2 & $41 / 166$ & $24.7(21-28)$ \\
\hline Algún ensayo & $69 / 166$ & $4 I .6(34.2-49.1)$
\end{tabular}

Oviedo, octubre 1997-marzo 1999

PCR, reacción en cadena de la polimerasa; EIA, enzimoinmunoanálisis; LBH, line blot hybridization; $\mathrm{HC2}$, hibrid capture; IC, intervalo de confianza 
identificación de VPH 16 fue de 70.6\% y para el VPH 18 de $88 \%$. Sin embargo, las discrepancias fueron superiores para la detección de los tipos VPH 31, 33 y 39; cinco muestras positivas para estos tipos mediante PCR-EIA fueron discordantes en tipo respecto de PCR$\mathrm{LBH}$, aunque todas fueron positivas para tipos de alto riesgo, mientras que las cuatro restantes fueron negativas (salvo una muestra que fue positiva por HC2).

El cuadro III muestra la comparación entre PCRLBH y HC2. De las 166 mujeres, la concordancia en ambos ensayos se reconoció en 139/166 muestras (84\%). De los 27 casos con resultado discordante, sólo dos de 14 de HC2 con valor negativo tenían un valor RLU en el umbral (0.90).

Se realizó un estudio citológico a todas las mujeres y sólo 10 casos se diagnosticaron como neoplasia intraepitelial cervical (NIC) I. Se identificaron tipos de alto riesgo oncogénico en $70 \%$ de estos casos por los dos métodos de PCR y en 80\% de los casos por HC2. Dos muestras de NIC I fueron negativas por los tres ensayos.

\section{Cuadro II \\ Comparación EN LA Detección de VPH MEDIANTE PCR-LBH Y PCR-EIA}

\begin{tabular}{lccc} 
PCR-EIA & PCR-LBH positivo & PCR-LBH negativo & Todos \\
Positivo & 32 & 17 & 49 \\
\hline Negativo & 10 & 107 & 117 \\
\hline Todos & 42 & 124 & 166
\end{tabular}

Oviedo, octubre 1997-marzo 1999

PCR, reacción en cadena de la polimerasa; EIA, enzimoinmunoanálisis; LBH, line blot hybridization

\begin{tabular}{|c|c|c|c|}
\hline & $\begin{array}{r}\text { Cu } \\
\text { VE ADN- }\end{array}$ & III & \\
\hline HC2. & MPARACIÓN & DA EN LOS TIPC & E ALTO \\
\hline RIESGO QL & E PUEDEN DET & ARSE POR AMBO & ISAYOS \\
\hline & PCR-LBH positivo & PCR-LBH negativo & Todos \\
\hline HC2 positivo & 28 & 13 & 41 \\
\hline $\mathrm{HC2}$ negativo & 14 & III & 125 \\
\hline Todos & 42 & 124 & 166 \\
\hline
\end{tabular}

Oviedo, octubre 1997-marzo 1999

PCR, reacción en cadena de la polimerasa; EIA, enzimoinmunoanálisis; LBH, line blot hybridization, $\mathrm{HC2}$, Irbid capture

\section{Discusión}

La detección del VPH está reconocida como instrumento útil para la disminución de la incidencia y mortalidad del cáncer de cuello uterino. Numerosos grupos evalúan la posibilidad de emplear distintas técnicas moleculares para la detección del VPH como herramienta en el cribado primario del cáncer cervical y la atención de las pacientes con diagnóstico de ASC-US y lesiones de bajo grado. $5,6,7,9,10$ Pese a ello, es importante que las técnicas aplicadas tengan una gran sensibilidad y especificidad para la detección de VPH. Como paso anterior a una posible utilización a gran escala de la detección del VPH, se ha calculado la prevalencia de la infección por VPH mediante tres protocolos diferentes en una población de alto riesgo para la infección. Los resultados demuestran que las tres técnicas de detección del VPH seleccionadas tuvieron un perfil de sensibilidad y especificidad similar. La prevalencia de la infección en esta población de alto riesgo fue semejante para cada uno de los ensayos utilizados (24.7 a $29.5 \%$ ), aunque la prevalencia global basada en un resultado positivo por algún ensayo fue de 41.6. Estos datos indican que si bien existe una razonable concordancia entre las técnicas seleccionadas, el uso de un solo ensayo en estudios de prevalencia tal vez no refleje la tasa real de infección. No obstante, y de acuerdo con otros estudios, las tres técnicas detectan entre 70 y $80 \%$ de los LSIL (no se diagnosticó ningún HSIL en esta serie), un porcentaje que coincide con los resultados observados en otros estudios, incluido el HSIL. ${ }^{5,6}$ Por último, una parte de estos LSIL en los cuales no se detectó VPH puede atribuirse a la subjetividad de la interpretación de la citología y una clasificación incorrecta de los cambios observados no relacionados con la infección, aunque también puede tratarse de una regresión de la infección anterior a la resolución de los cambios morfológicos; también son posibles infecciones con VPH de bajo riesgo que no incluyen las pruebas.

Los métodos de PCR basados en la amplificación de ADN de VPH poseen una alta sensibilidad para la detección del virus en muestras cervicovaginales. ${ }^{11}$ Estos ensayos presentan el problema de la posible contaminación con producto amplificado, por lo que deben realizarse en laboratorios especializados. Por otro lado, los métodos comercializados de amplificación de la señal (HC2) tienen en teoría menor sensibilidad pero un menor riesgo de contaminación, y por ello son más fáciles de introducir en laboratorios de diagnóstico. Sin embargo, es importante remarcar que en su aplicación clínica, la sensibilidad para la detección de ADN de VPH puede ser de menor relevancia que la especi- 
ficidad de un ensayo para la identificación de mujeres con lesiones cervicales precancerosas.

Si se analizan las discrepancias observadas, según sea la técnica utilizada, $16 \%$ de los casos entre las técnicas de PCR-EIA y PCR-LBH es discordante. No obstante, si la comparación entre las dos PCR se limita a los cinco tipos identificados por PCR-EIA, se muestra una notoria concordancia para la identificación de VPH 16 y 18 (la concordancia para los otros tipos es inferior). Estas diferencias son explicables ya que los cebadores PGYM09/11 se rediseñaron a partir del sistema MY09/11 y estudios previos demuestran que poseen mayor potencial para tipificar los VPH para los cuales se rediseñaron. Pese a ello, los cebadores MY09/11 con la sonda genérica identifican con mayor facilidad a mujeres positivas. ${ }^{8,11}$ En consecuencia, existe variabilidad en la sensibilidad de la detección de los diferentes tipos de VPH según sea la técnica empleada. Otros estudios muestran también notables discrepancias en la detección específica cuando comparan dos PCR basadas en otros cebadores (GP5+/GP6+ o MY09/11). ${ }^{12}$ Alrededor de $50 \%$ de las mujeres tenía más de un tipo de alto riesgo. La importancia clínica de las infecciones múltiples todavía no está bien definida, aunque estudios preliminares indican que un alto porcentaje de las lesiones de alto grado posee infecciones múltiples en comparación con las lesiones de bajo grado. ${ }^{13}$

En muestras de carcinoma, la prevalencia de la infección múltiple es menor, lo que podría explicarse si se considera la hipótesis clonal de la carcinogénesis cervical. ${ }^{14}$ En este sentido, las infecciones múltiples podrían reflejar una mayor tolerancia inmunológica a la infección por VPH, con la acumulación consecuente de infecciones. Desde este punto de vista, las infecciones múltiples pueden representar un marcador de persistencia de la infección, lo cual han demostrado algunos estudios como un posible factor de progresión de la lesión. ${ }^{15}$

En este análisis, HC2 detectó a menos mujeres positivas que las técnicas de PCR. Estas diferencias fueron menores respecto de la PCR-LBH (41 contra 42) en comparación con la PCR-EIA mediante la sonda genérica (41 contra 49). La discrepancia en los casos PCR-LBH+/HC2- puede atribuirse a la gran sensibilidad de los ensayos de PCR, aunque ésta no permite explicar los 13 casos positivos y negativos a HC2 para PCR. Con anterioridad se indicó que las sondas de HC2 pueden suscitar reacciones cruzadas con otros tipos que no están presentes en la PCR-LBH y que corresponden a tipos de bajo riesgo. Estas muestras pueden considerarse como "falsos positivos" para HC2. No obstante, por otro lado, fallas en la amplificación de la PCR por deleciones o cambios en la secuencia viral pueden también afectar el resultado de la PCR.

Como se ha mostrado en este trabajo, las dos pruebas moleculares que presentan los niveles de sensibilidad y especificidad deseados más utilizadas en la detección de VPH son la captura de híbridos y las técnicas basadas en PCR, si bien ambas poseen ventajas y desventajas.

La captura de híbridos es una técnica que puede aplicarse con facilidad en los laboratorios, ya que no requiere instalaciones especiales como personal con amplia experiencia en técnicas moleculares, aunque puede tener un cierto grado de reacciones cruzadas con otros tipos de bajo riesgo oncogénico, los denominados falsos positivos. ${ }^{16}$ Por el momento, la técnica no permite conocer el tipo específico de VPH, lo que en un futuro puede ser un factor limitante si se confirma la más rápida progresión de las infecciones por VPH 16 y $18 .{ }^{15}$

Las técnicas basadas en PCR permiten conocer el tipo específico y las infecciones múltiples, lo que posibilita el seguimiento particular de la persistencia de la infección. Sin embargo, tiene desventajas, como la necesidad de contar con espacios adecuados y personal con experiencia para minimizar los riesgos inherentes a las técnicas de amplificación. Estos factores limitan su incorporación en muchos laboratorios. Por lo tanto, es necesario focalizar los esfuerzos en el desarrollo de un método rápido, fácil, sensible y específico para identificar tipos de alto riesgo oncogénico de VPH; más aún, debe tener una aplicación a gran escala y costo moderado para que todas las mujeres tengan acceso a él.

En conclusión, los resultados muestran tres métodos comparables en la detección de la prevalencia de la infección por VPH. Es recomendable la utilización de pruebas estandarizadas. La introducción de nuevas pruebas de detección de VPH debe acompañarse de una evaluación de la validez interna de las mismas.

\section{Referencias}

I.Walboomers IMM, Jacobs MV, Manos MM, Bosch FX, Kummer JA, Shah $\mathrm{KV}$, et al. Human papillomavirus is a necessary cause of invasive cervical cancer worldwide.J Pathol 1999;189:12-19.

2. National Cancer Institute Workshop. The 1988 Bethesda system for reporting cervical/vaginal cytologic diagnoses. JAMA 1989;262:931-934. 3. National Cancer Institute Workshop. The revised Bethesda system for reporting cervical/vaginal diagnoses. JAMA 1992;267:1892.

4. Sherman ME, Schiffman MH, Lorincz AT, Manos MM, Scott DR, Kurman $\mathrm{RJ}$, et al. Toward objective quality assurance in cervical cytopathology. 
Correlation of cytopathologic diagnoses with detection of high-risk human papillomavirus types. Am J Clin Pathol 1994;102:182-187. 5. Manos MM, Kinney WK, Hurley LB, Sherman ME, Shieh-Ngai J, Kurman RJ, et al. Identifying women with cervical neoplasia using human papillomavirus DNA testing for equivocal Papanicolaou results. JAMA 1999;281:1605-1610.

6. Solomon D, Schiffman M, Tarone R. ALTS Study group. Comparison of three management strategies for patients with atypical squamous cells of undetermined significance: baseline results from a randomized trial. J Natl Cancer Inst 2001;93:293-299.

7. Canadas MP, Martinez F, Sanjose S, Valls I, Lloveras B, Bosch FX, et al. Detection of human papillomavirus DNA by PCR in high-risk women. Validation of a protocol. Enferm Infecc Microbiol Clin 1998;16:400-403. 8. Gravitt PE, Peyton CL,Apple RJ,Wheeler CM. Genotyping of 27 human papillomavirus types by using $\mathrm{LI}$ consensus PCR products by a single-hybridization, reverse line blot detection method.J Clin Microbiol 1998;36:3020-3027.

9. Cox JT. Evaluating the role of VPH testing for women with equivocal Papanicoalou test findings (editorial). JAMA 1999;28I:1645-1647.

10. Ho L, Terry G, Londesborough P, Cuzick J, Lorenzato F, Singer A. Human papillomavirus DNA detection in the management of women with twice mildly abnormal cytological smears. J Med Virol 2003;69:1|8-121.
II. Gravitt PE, Peyton CL, Alessi TQ,Wheeler CM, Coutlée F, Hildesheim A, et al. Improved amplification of genital human papillomaviruses. J Clin Microbiol 2000;38:357-36I.

12. Fuessel AL, He Q, Rady PL, et al. Nested PCR with the PGMY09/II and GP5 $(+) / 6(+)$ primer sets improves detection of HPV DNA in cervical samples. JVirol Methods 2004; I22(I):87-89.

13. Kleter B, van Doorn LJ, Schrauwen L, Molijn A, Sastrowijoto S, ter Schegget J, et al. Development and clinical evaluation of a highly sensitive PCR-reverse hybridization line probe assay for detection and identification of anogenital human papillomavirus. J Clin Microbiol 1999;37(8):2508-25I7.

14. Ponten J, Guo Z. Precancer of the human cervix. Cancer Surv 1998;32:201-229.

15. Wallin KL,Wiklund F, Angstrom T, Bergman F, Stendahl U,Wadell G, et al. Type'specific persistence of human papillomavirus DNA before the development of invasive cervical cancer. N Engl J Med 1999;341:1633-1638.

16. Soderlund-Strand A, Rymark P, Andersson P, Dillner J, Dillner L. Comparison between the hybrid capture II test and a PCR-based human papillomavirus detection method for diagnosis and posttreatment follow-up of cervical intraepithelial neoplasia. J Clin Microbiol 2005;43(7):3260-3266. 